\title{
Residual Stresses in Case Hardened Materials
}

\author{
K. Palaniradja*, N. Alagumurthi and V. Soundararajan \\ Department of Mechanical Engineering, Pondicherry Engineering College, Pondicherry - 605 014, India
}

\begin{abstract}
Fatigue behavior of case hardened parts depend to a great extent on the type of residual stresses developed in the components. Topography and metallurgical effects were the two elements which contribute much to surface integrity. Micro hardness of the gas carburized (EN 33 and EN 36) and Induction hardened (AISI 1040 and AISI 6150) specimens obtained during experiments, showed that there was gradual decrease of hardness from surface to sub-surface. Results also showed that more the hardness and case depth, the more was the residual stress. The optimum results gave the maximum compressive residual stress in both the gas carburizing and Induction hardening process irrespective of the mechanisms involved in the process. The X-ray diffraction test showed that the distribution of residual stress was uniform both on the surface and beneath the surface. The magnitude and distribution of residual stress obtained from the experiment agreed with the FEM results found in literatures.
\end{abstract}

Keywords: Residual stress, case hardening, tensile stress, compressive stress, micro hardness.

\section{INTRODUCTION}

In many applications, like Automobiles, heavy duty machines, et., where the machine elements are subjected fatigue loading, Gas carburized and Induction hardened components are used. Fatigue behaviour of case hardened parts depends to a great extent on the type of residual stress developed in the components. In Gas Carburizing and Induction hardening the heating and sudden cooling causes phase transformations on the surface layer and beneath the surface of the workpiece. Heat treatment temperature, Quenching Temperature, Type of Quenchant, Quenching period, heat treatment period are major variables, which influence the phase transformation [1].

Phase transformation affects the surface layer characteristics/surface integrity. The concept of surface integrity cannot be defined one dimensionally and does not only embrace the surface hardness, surface roughness, case depth or its geometrical shape, but also the characteristics of the surface and the layers directly underneath it. It comprehends the mechanical, physical-chemical, metallurgical and technological properties. Surface integrity is defined as the unimpaired surface conditions, which are developed in hardware by using controlled heat treatment operations [2]. Two elements comprise the surface integrity. The first is the topography and the second is the metallurgical alternations produced at or near the surface. It thus includes dimensional accuracy, residual stresses and metallurgical damage of the heat treated component.

Surface integrity assumes importance for the reasons listed below:

* Higher stress levels to which the materials are subjected

*Address correspondence to this author at the Department of Mechanical Engineering, Pondicherry Engineering College, Pondicherry-605014, India; Tel: 91413 2655281-287, Ext. 252,259; Fax: 91413 2655101;

E-mail: palaniradja72@rediffmail.com
* Reliability demands are stringent

* Components with critical sections are becoming more in use

The surface integrity of any part produced depends on

* The state of material before the heat treatment starts.

* The processing variable

* The energy levels during the case hardening process and

* The type of quenchant and rate of quenching

Of all the properties that describe the surface layer characteristics residual stresses regarded as the most representative one as far as mechanical applications are concerned,. In heat treated components, residual stresses developed are due to phase transformation and non-uniform deformation during heating and cooling cycles [3]. In case of phase transformation, if the transformation is martensite to ferrite or pearlite the volume decreases hindered by the bulk material produces tensile residual stresses. If the phase transformation is ferrite to pearlite to martensite the volume increases hindered by the bulk material produces compressive residual stresses. These stresses influence the mechanical properties like fatigue strength depending on their nature, magnitude and distribution across the body. There is basically no material or situation free of this stresses. Hence, the general interest is the recognition and measurement of these residual stresses [4].

With the recent improvement on machines to measure the residual stress through $\mathrm{XRD}$, the interest on the knowledge to control such stresses has increased. This interest has its importance due to the fact that the presence of the residual stress interferes with the fatigue strength of the Materials [5]. 


\section{RESIDUAL STRESS IN GAS CARBURIZING}

The development of residual stresses, final microstructure and mechanical properties in the case and core of the carburized components depends on complex interactions among steels composition, component size and geometry, carburizing and subsequent austenitizing process parameters., heat transfer associated during quenching and time and temperature parameters of tempering.

Component geometry (size and shape) together with heat transfer associated with quenching conditions (i.e., cooling performance of the quenchant, agitation etc.,) affect the final residual stress state developed in casehardened steels as a result of quenching. Carburized microstructure is almost always tempered to transform the unstable and brittle martensite into stable tempered martensite $[6,7]$. Tempering decreases residual stresses and this is promoted by increasing the tempering temperature.

With this in mind an experimental investigation is performed using EN33 (AISI 3310) and EN36 (AISI 8620) steel material to study the surface integrity issue with main focus on Residual stress in Gas Carburizing Process.

The Fig. (1) shows the measurement of residual stress in the gas carburized components. On the helix (a), groove (b), knurled region(c) and cylindrical surface (d) of the pinion material residual stresses are measured using residual stress analyzer by X-ray diffraction technique and the average surface residual stress is taken for the analysis [8]. The residual stress beneath the top surface is measured upto a maximum depth of $1 \mathrm{~mm}$ in the intervals of $0.1 \mathrm{~mm}$.

Table 1 gives the details on the materials $[9,10]$ subjected for Gas Carburizing (Residual stress analysis). Table 2 shows the operating parameters and their levels adopted in Gas Carburising process. Table $\mathbf{3}$ gives the experimental design matrix and Table 4, shows the test results.

The experiments have been conducted based on L27 orthogonal array system proposed in Taguchis' Mixed level series DOE with interactions as given below:

i) Furnace Temperature vs Quenching Time (AxB)

ii) Furnace Temperature vs Tempering Temperature $(\mathrm{AxC})$

\section{RESIDUAL STRESS IN INDUCTION HARDENING}

In Induction hardening, the components are heated usually for a few seconds only. The hardening temperature varies from $760-800^{\circ} \mathrm{C}$. The major influencing variables in Induction Hardening are the Power potential, Scan speed and Quench flow rate. The process variables are having a definite relation with hardness and volume fraction of martensite of the hardened components [11]. The attainment of correct combination of surface hardness, hardness penetration depth

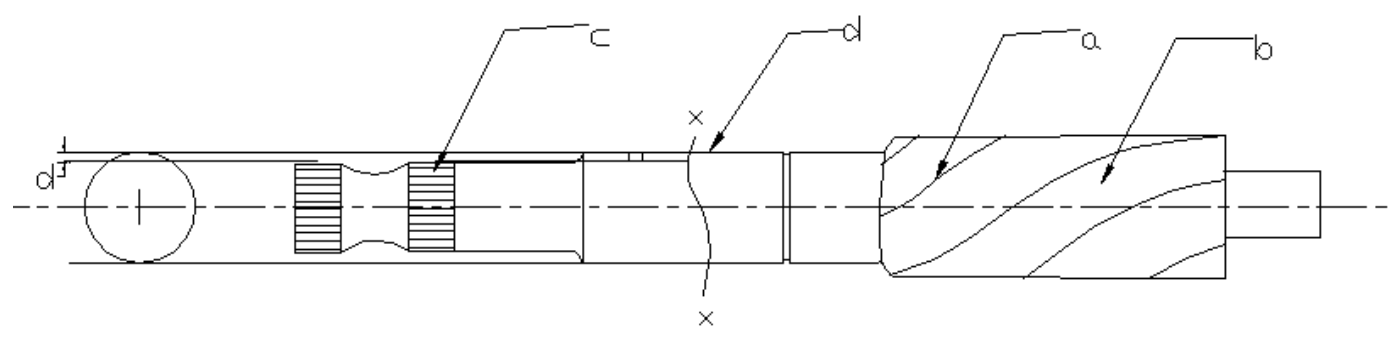

Fig. (1). Residual stress measurement locations on the Gas carburized component.

Table 1. Materials Used in Gas Carburizing

\begin{tabular}{|c|c|c|c|c|}
\hline S. No. & Type & Designation & Chemical Composition in Percentage & Size \\
\hline 01 & Nickel alloy steel & EN 33 & $\mathrm{C}-0.15 \%, \mathrm{Si}-0.35 \%, \mathrm{Mn}-0.60 \%, \mathrm{Cr}-0.30 \%, \mathrm{Ni}-3.5 \%$, S\&P each $-0.05 \%$ & $\begin{array}{c}\text { Diameter }=17.3 \mathrm{~mm} \\
\text { Length }=150 \mathrm{~mm}\end{array}$ \\
\hline
\end{tabular}

Table 2. Gas Carburizing-Operating Conditions

\begin{tabular}{|c|c|c|c|c|c|}
\hline S. No. & Variables & Notation & Level 1 & Level 2 & Level 3 \\
\hline \hline 1 & Furnace temperature & A & $870^{\circ} \mathrm{C}$ & $910^{\circ} \mathrm{C}$ & $940^{\circ} \mathrm{C}$ \\
\hline 2 & Quenching Time & B & 60 minutes & 90 minutes & 120 minutes \\
\hline 3 & Tempering Temperature & C & $150^{\circ} \mathrm{C}$ & $200^{\circ} \mathrm{C}$ & 100 minutes \\
\hline 4 & Tempering Time & D & 80 minutes & $150^{\circ} \mathrm{C}$ & No Preheating \\
\hline 5 & Preheating & E & No Preheating & 120 minutes \\
\hline
\end{tabular}


Table 3. Experimental Design Matrix

\begin{tabular}{|c|c|c|c|c|c|c|c|c|c|}
\hline 1 & 1 & 1 & 1 & 1 & 1 & 1 & 1 & 1 & 1 \\
\hline 2 & 1 & 1 & 1 & 1 & 2 & 2 & 2 & 2 & 2 \\
\hline 4 & 1 & 2 & 2 & 2 & 1 & 1 & 1 & 2 & 2 \\
\hline 5 & 1 & 2 & 2 & 2 & 2 & 2 & 2 & 3 & 3 \\
\hline 6 & 1 & 2 & 2 & 2 & 3 & 3 & 3 & 1 & 1 \\
\hline 9 & 1 & 3 & 3 & 3 & 3 & 3 & 3 & 2 & 2 \\
\hline 10 & 2 & 1 & 2 & 3 & 1 & 2 & 3 & 1 & 2 \\
\hline 11 & 2 & 1 & 2 & 3 & 2 & 3 & 1 & 2 & 3 \\
\hline 12 & 2 & 1 & 2 & 3 & 3 & 1 & 2 & 3 & 1 \\
\hline 13 & 2 & 2 & 3 & 1 & 1 & 2 & 3 & 2 & 3 \\
\hline 14 & 2 & 2 & 3 & 1 & 2 & 3 & 1 & 3 & 1 \\
\hline 19 & 3 & 1 & 3 & 2 & 1 & 3 & 2 & 1 & 3 \\
\hline 20 & 3 & 1 & 3 & 2 & 2 & 1 & 3 & 2 & 1 \\
\hline 21 & 3 & 1 & 3 & 2 & 3 & 2 & 1 & 3 & 2 \\
\hline 22 & 3 & 2 & 1 & 3 & 1 & 3 & 2 & 2 & 1 \\
\hline 23 & 3 & 2 & 1 & 3 & 2 & 1 & 3 & 3 & 2 \\
\hline 24 & 3 & 2 & 1 & 3 & 3 & 2 & 1 & 1 & 3 \\
\hline 25 & 3 & 3 & 2 & 1 & 1 & 3 & 2 & 3 & 2 \\
\hline 26 & 3 & 3 & 2 & 1 & 2 & 1 & 3 & 1 & 3 \\
\hline 27 & 3 & 3 & 2 & 1 & 3 & 2 & 1 & 2 & 1 \\
\hline
\end{tabular}

Table 4. Gas Carburizing Test Results Materials: EN 33 and EN 36

\begin{tabular}{|c|c|c|c|c|c|c|}
\hline S. No. & \multicolumn{2}{|c|}{ Hardness in HRA } & \multicolumn{2}{|c|}{ Case Depth in mm } & \multicolumn{2}{|c|}{ Residual Stress in MPa } \\
\hline 02 & 78.5 & 78.0 & 0.80 & 0.75 & -430 & \begin{tabular}{|l|}
-423 \\
\end{tabular} \\
\hline 03 & 79.0 & 77.0 & 0.75 & 0.80 & -428 & -430 \\
\hline 04 & 79.0 & 77.5 & 0.80 & 0.85 & -432 & -432 \\
\hline 07 & 81.0 & 80.0 & 0.65 & 0.70 & -430 & -434 \\
\hline 08 & 78.0 & 80.5 & 0.70 & 0.70 & -423 & -432 \\
\hline 09 & 79.0 & 76.0 & 0.70 & 0.70 & -428 & -422 \\
\hline 10 & 79.0 & 77.0 & 0.75 & 0.70 & -428 & -424 \\
\hline 11 & 79.0 & 77.0 & 0.85 & 0.85 & -438 & -426 \\
\hline 12 & 79.5 & 78.0 & 0.85 & 0.80 & -440 & -427 \\
\hline 17 & 81.0 & 78.5 & 0.75 & 0.85 & -438 & -427 \\
\hline 18 & 77.0 & 76.0 & 0.85 & 0.85 & -432 & -421 \\
\hline 19 & 78.0 & 77.5 & 0.85 & 0.75 & -436 & -427 \\
\hline 20 & 80.5 & 80.0 & 0.85 & 0.70 & -442 & -432 \\
\hline 21 & 79.0 & 79.5 & 0.70 & 0.80 & -431 & -429 \\
\hline 22 & 78.5 & 76.5 & 0.80 & 0.85 & -433 & -424 \\
\hline 23 & 81.5 & 81.5 & 0.80 & 1.00 & -448 & -460 \\
\hline 24 & 79.0 & 78.0 & 0.95 & 0.90 & -434 & -429 \\
\hline 25 & 80.0 & 78.5 & 0.80 & 0.90 & -438 & -431 \\
\hline 26 & 79.5 & 80.0 & 0.80 & 0.95 & -434 & -445 \\
\hline 27 & 80.0 & 77.0 & 0.90 & 0.90 & -446 & -427 \\
\hline
\end{tabular}




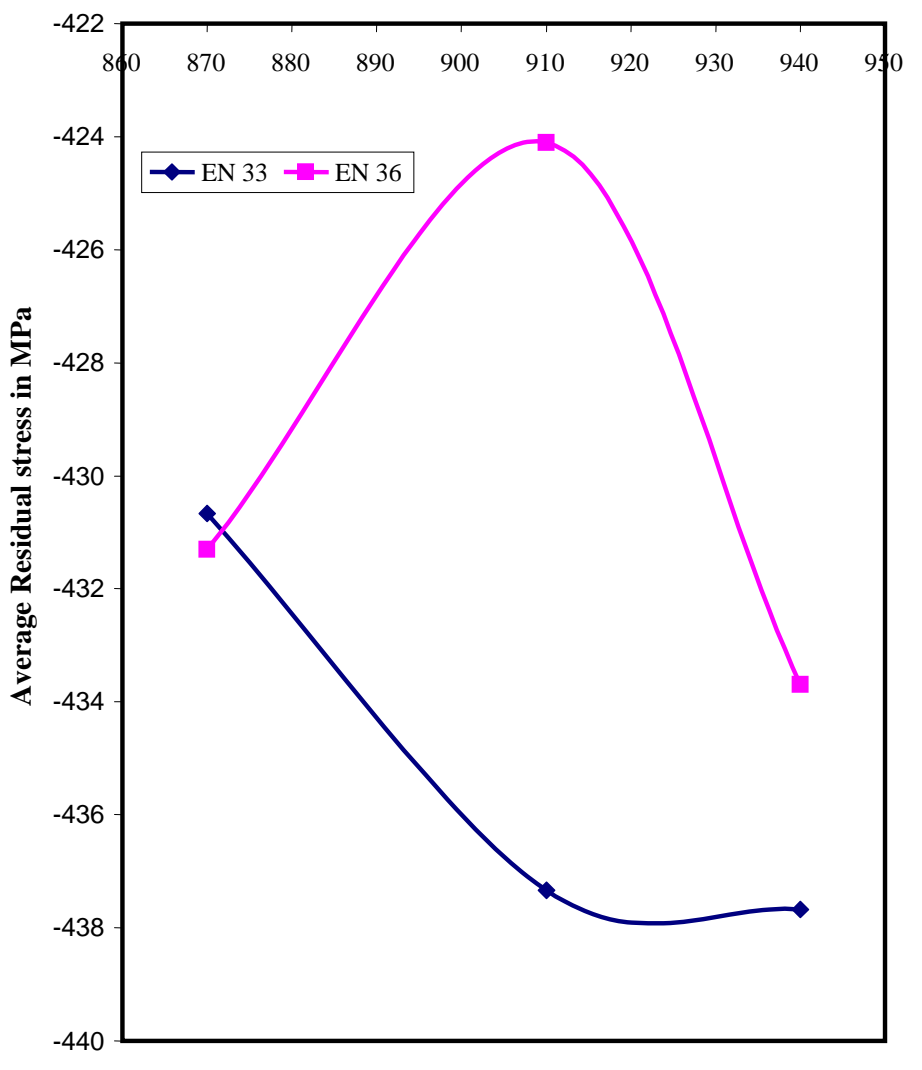

Furnace Temperature in degree Celsius

(a)

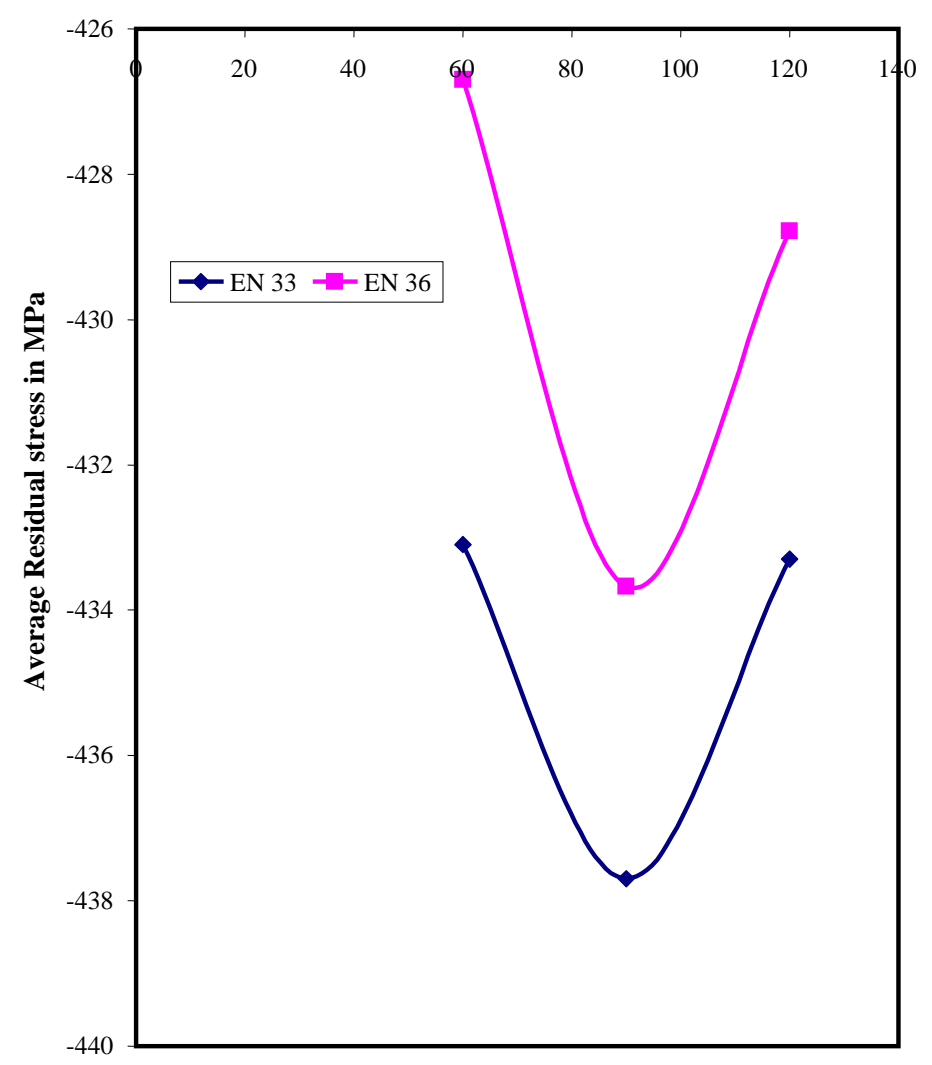

Quenching time in minutes

(b)
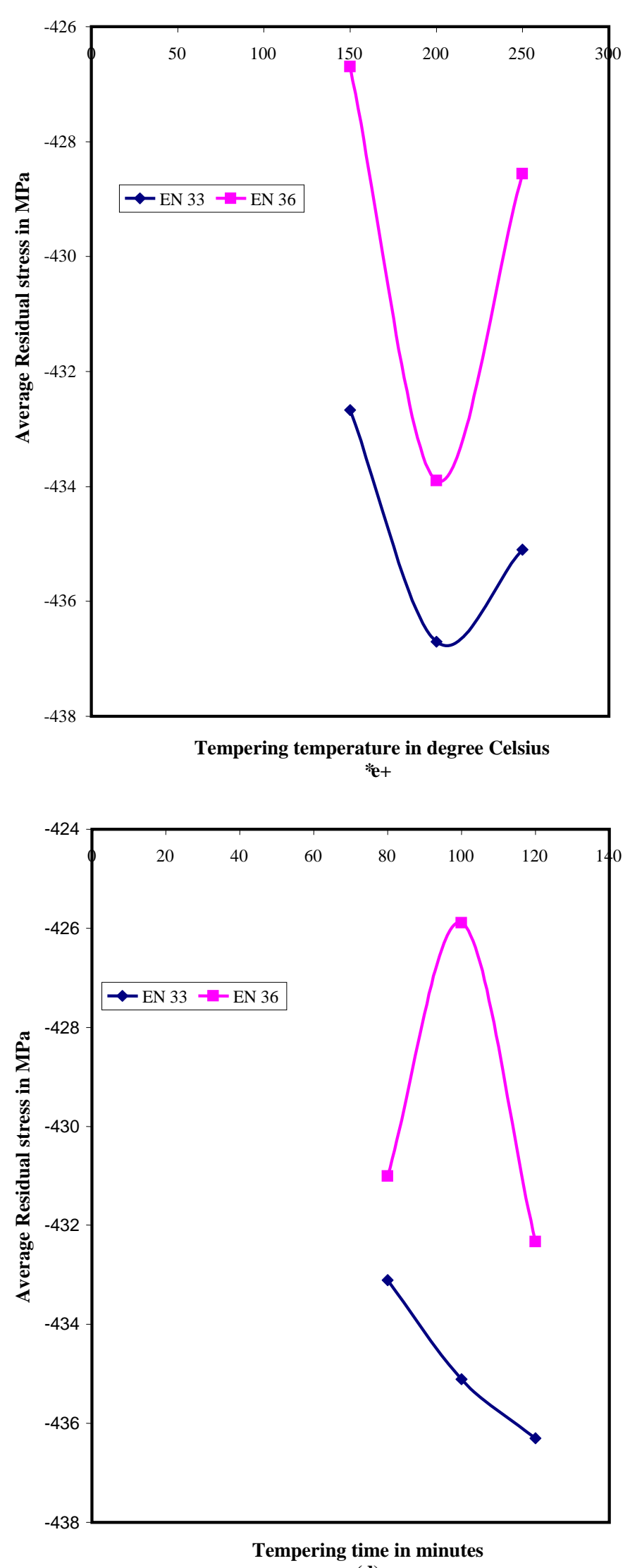

(d) 
(Fig. 2) contd.....

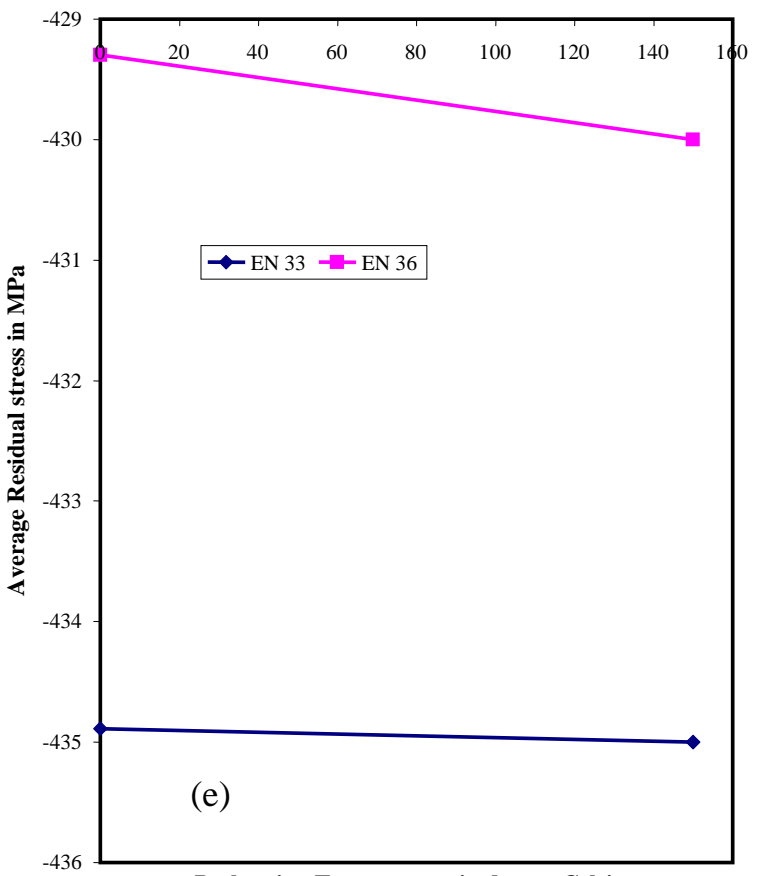

Preheating Temperature in degree Celsius

(e)

Fig. (2). (a-e) Process variables $v s$ residual stress.

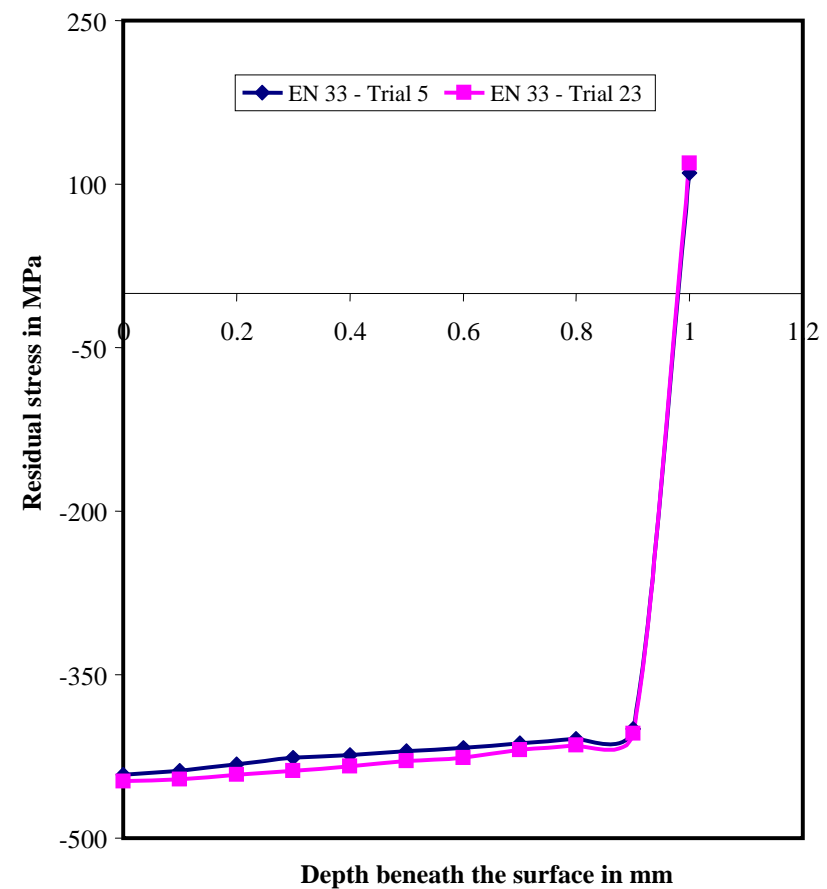

Fig. (3). Depth beneath the surface vs Residual stress (EN 33 - Gas Carburizing Process).

Table 5. Residual Stress and Micro Hardness Values of the Gas Carburized Component for the Selected set of Trials Material: EN 33

\begin{tabular}{|c|c|c|c|c|}
\hline \multirow{2}{*}{ Depth Beneath the Surface in $\mathrm{mm}$} & \multicolumn{2}{|c|}{ Micro Hardness in VHN } & \multicolumn{2}{|c|}{ Residual Stress in MPa } \\
\hline & Trial 5 & Trial 23 & Trial 5 & Trial 23 \\
\hline Surface & 610 & 620 & -442 & -448 \\
\hline 0.1 & 600 & 614 & -438 & -446 \\
\hline 0.2 & 595 & 600 & -432 & -442 \\
\hline 0.3 & 590 & 594 & -426 & -438 \\
\hline 0.4 & 585 & 590 & -424 & -434 \\
\hline 0.5 & 584 & 587 & -420 & -429 \\
\hline 0.6 & 582 & 584 & -417 & -426 \\
\hline 0.7 & 579 & 576 & -413 & -419 \\
\hline 0.8 & 572 & 564 & -409 & -415 \\
\hline 0.9 & 564 & 561 & -400 & -404 \\
\hline 1.0 & 550 & 550 & +110 & $\begin{array}{l}+119 \\
\end{array}$ \\
\hline
\end{tabular}

Table 6. Residual Stress and Micro Hardness Values of the Gas Carburized Component for the Selected Set of Trials Material: EN 36

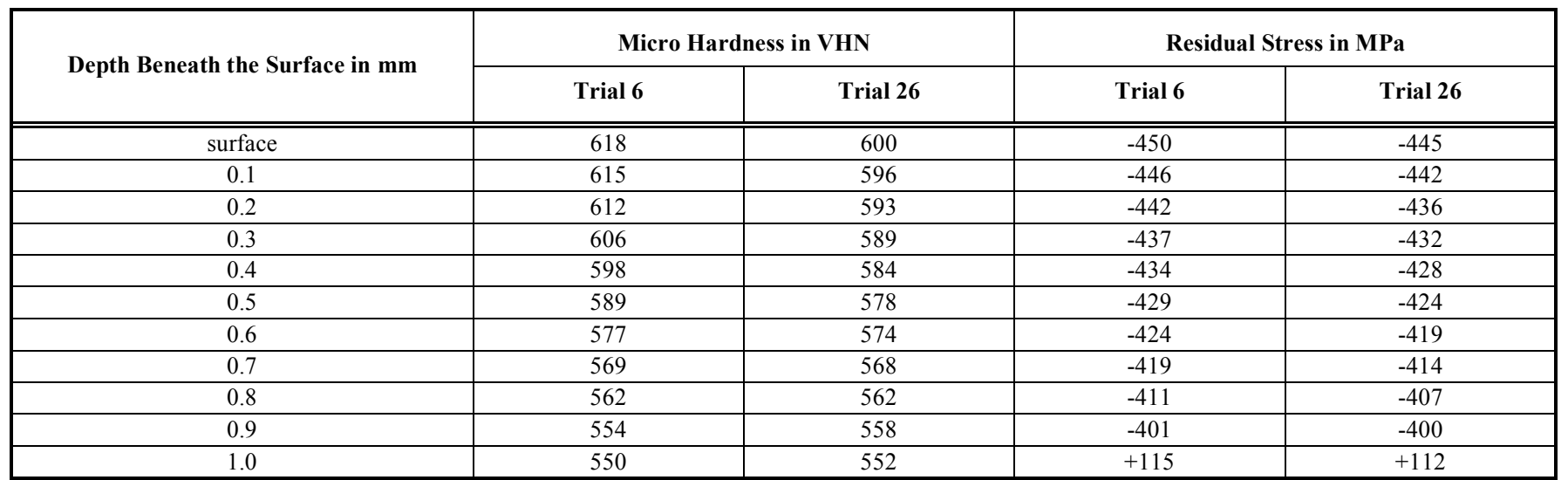




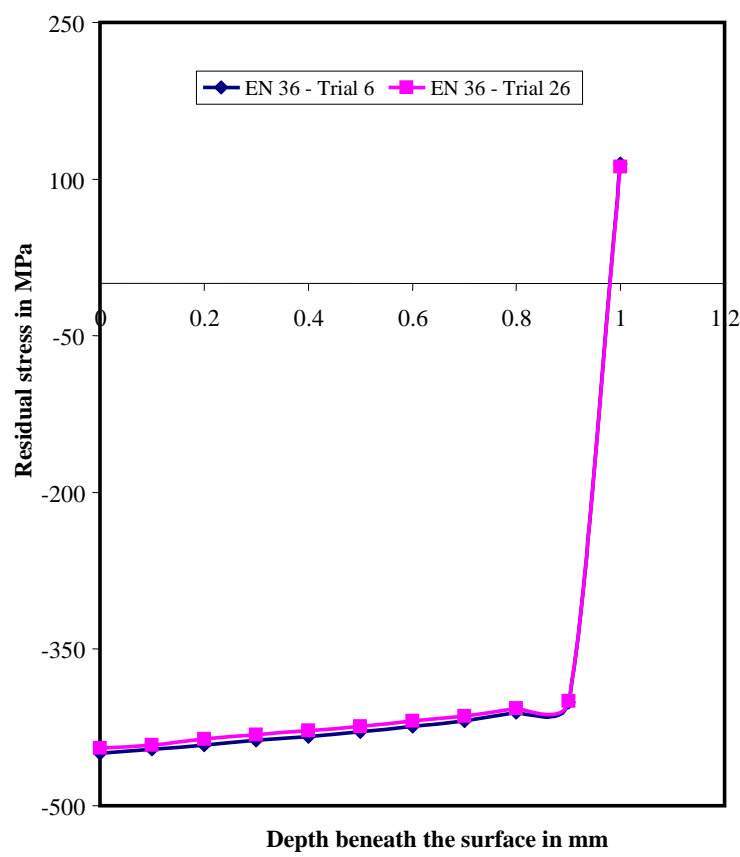

Fig. (4). Depth beneath the surface vs Residual stress (EN 36 - Gas Carburizing Process). and high magnitude of compressive residual stress with permitted level of distortion requires the use of proper and optimized process variables.

The surface residual stress and the sub-surface residual stress are of great importance on the fatigue resistance of the materials [12]. Number of researchers report that if those stresses are of compressive natures improve the resistance to fatigue whereas if those stresses are of tensile nature depending on their magnitude they contribute to a decline in the fatigue resistance [13]. In order to verify the behaviour of the residual stress in the surface and sub-surface of the Induction hardened components, experiments have been conducted.

The Fig. (5) shows the details on the measurement of residual stress in the Induction hardened components. The measurement was taken at three places, namely teeth (a), groove (b) and cylindrical surface (c). Residual stresses are measured using residual stress analyzer by X-ray diffraction technique and the average surface residual stress is taken for the analysis [14]. The residual stress beneath the top surface is measured upto a maximum depth of $1 \mathrm{~mm}$ in the intervals of $0.1 \mathrm{~mm}$.

Table 7 gives the details on the materials subjected for Induction Hardening (Residual stress analysis). Table 8 shows the operating variables and their levels adopted in

Table 7. Materials Used for Induction Hardening (Residual Stress Analysis)

\begin{tabular}{|c|c|c|c|c|}
\hline S. No. & Type & Designation & Chemical Composition in Percentage & Size \\
\hline 01 & Unalloyed carbon steel & AISI 1040 & C- $0.35 \%$, Si- $0.10 \%$, Mn- $0.60 \%$ S\&P each $0.06 \%$ & $\begin{array}{l}\text { Diameter }=23 \mathrm{~mm} \\
\text { Length }=200 \mathrm{~mm}\end{array}$ \\
\hline
\end{tabular}

Table 8. Induction Hardening Operating Conditions

\begin{tabular}{|c|c|c|c|c|c|c|c|c|c|}
\hline S. No & Variables & Unit & Notation & \multicolumn{3}{|c|}{ Levels actual } & \multicolumn{3}{|c|}{ Code } \\
\hline 1 & Power potential & $\mathrm{kW} /$ inch $^{2}$ & $\mathrm{P}$ & 5.5 & 7.05 & 8.5 & L1 & L2 & L3 \\
\hline 2 & Scan speed & $\mathrm{m} / \mathrm{min}$ & $\mathrm{S}$ & 1.34 & 1.72 & 2.14 & $\mathrm{~L} 1$ & $\mathrm{~L} 2$ & L3 \\
\hline 3 & Quench flow rate & Litres/min & $\mathrm{Q}$ & 15 & 17.5 & 20 & L1 & L2 & L3 \\
\hline
\end{tabular}

Table 9. Experimental Design Matrix

\begin{tabular}{|c|c|c|c|c|c|c|c|c|c|c|c|}
\hline \multirow{2}{*}{ S. No. } & \multicolumn{3}{|c|}{ Factors and Treatment } & \multirow{2}{*}{ S. No. } & \multicolumn{3}{|c|}{ Factors and Treatment } & \multirow{2}{*}{ S. No. } & \multicolumn{3}{|c|}{ Factors and Treatment } \\
\hline & $\mathbf{P}$ & $\mathbf{S}$ & $\mathbf{Q}$ & & $\mathbf{P}$ & $\mathbf{S}$ & $\mathbf{Q}$ & & $\mathbf{P}$ & $\mathbf{S}$ & $\mathbf{Q}$ \\
\hline 1 & $\mathrm{~L} 1$ & L1 & L1 & 10 & $\mathrm{~L} 2$ & L1 & $\mathrm{L} 1$ & 19 & L3 & L1 & L1 \\
\hline 2 & L1 & L1 & L2 & 11 & L2 & L1 & L2 & 20 & L3 & L1 & L2 \\
\hline 3 & L1 & L1 & L3 & 12 & L2 & L1 & L3 & 21 & L3 & L1 & L3 \\
\hline 4 & L1 & $\mathrm{L} 2$ & L1 & 13 & L2 & $\mathrm{L} 2$ & L1 & 22 & L3 & L2 & L1 \\
\hline 5 & $\mathrm{~L} 1$ & $\mathrm{~L} 2$ & L2 & 14 & L2 & L2 & L2 & 23 & L3 & $\mathrm{L} 2$ & L2 \\
\hline 6 & L1 & $\mathrm{L} 2$ & L3 & 15 & $\mathrm{~L} 2$ & L2 & L3 & 24 & L3 & L2 & L3 \\
\hline 7 & L1 & L3 & L1 & 16 & L2 & L3 & L1 & 25 & L3 & L3 & $\mathrm{L} 1$ \\
\hline 8 & L1 & L3 & L2 & 17 & L2 & L3 & L2 & 26 & L3 & L3 & L2 \\
\hline 9 & L1 & L3 & L3 & 18 & L2 & L3 & L3 & 27 & L3 & L3 & L3 \\
\hline
\end{tabular}




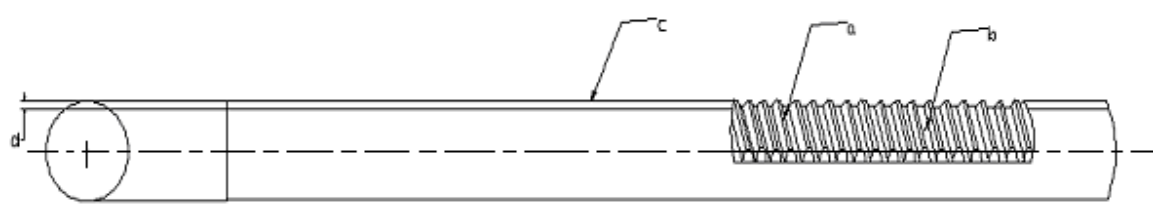

Fig. (5). Residual stress measurement locations on the Induction hardened component.

Induction hardening process. Table $\mathbf{9}$ shows the Experimental design matrix. Tables 10-12 show the test results.

The experiments have been conducted based on $3^{3}$ full factorial DOE.

\section{RESULTS AND DISCUSSION}

Micro hardness of the Gas carburized (EN 33 and EN 36) and Induction hardened (AISI 1040 and AISI 6150) specimens are found by using Vickers microhardness tester and reported in the Tables 5, 6, 12 and 13. The higher hardness resulted from the outer surface is due to the formation of martensite, which is obtained during the diffusion, and phase transformation of surface layers with self-quenching. Micro hardness analysis gives that there is a gradual decrease of hardness from surface to sub-surface.

The surface hardness in HRA, case depth in $\mathrm{mm}$, Residual stress in $\mathrm{MPa}$ for different experimental combinations of Gas carburized specimens are shown in Table 4. Study indicates that more the hardness and case

Table 10. Induction Hardening Test Results Material: AISI 1040

\begin{tabular}{|c|c|c|c|c|c|c|c|c|}
\hline S. No. & \multicolumn{3}{|c|}{ Factors and Treatment } & $\begin{array}{l}\text { Hardness in } \\
\text { HRA }\end{array}$ & $\begin{array}{c}\text { Distortion in } \\
\mathbf{m m}\end{array}$ & $\begin{array}{l}\text { Case Depth Below } \\
\text { the Teeth in } \mathrm{mm}\end{array}$ & $\begin{array}{l}\text { Case Depth Back } \\
\text { of the Bar in mm }\end{array}$ & $\begin{array}{c}\text { Residual Stress } \\
\text { in MPa }\end{array}$ \\
\hline 2 & L1 & L1 & $\mathrm{L} 2$ & 78.0 & 2.15 & 2.20 & 3.80 & -736 \\
\hline 3 & L1 & L1 & L3 & 79.0 & 1.90 & 1.85 & 3.20 & -742 \\
\hline 5 & L1 & $\mathrm{L} 2$ & $\mathrm{~L} 2$ & 80.0 & 1.60 & 1.80 & 2.70 & -746 \\
\hline 6 & L1 & $\mathrm{L} 2$ & L3 & 82.0 & 2.10 & 2.20 & 4.20 & -750 \\
\hline 7 & L1 & L3 & $\mathrm{L} 1$ & 83.0 & 2.40 & 2.30 & 2.30 & -744 \\
\hline 8 & L1 & L3 & $\mathrm{L} 2$ & 74.0 & 1.30 & 1.80 & 2.90 & -734 \\
\hline 12 & $\mathrm{~L} 2$ & L1 & $\mathrm{L} 3$ & 77.0 & 1.70 & 1.90 & 1.90 & -734 \\
\hline 13 & L2 & $\mathrm{L} 2$ & $\mathrm{~L} 1$ & 78.0 & 2.00 & 1.90 & 3.10 & -737 \\
\hline 14 & L2 & L2 & $\mathrm{L} 2$ & 74.0 & 2.40 & 2.50 & 2.30 & -727 \\
\hline 15 & L2 & $\mathrm{L} 2$ & $\mathrm{~L} 3$ & 76.0 & 2.30 & 2.30 & 3.30 & -732 \\
\hline 16 & L2 & L3 & $\mathrm{L} 1$ & 78.0 & 1.30 & 1.35 & 2.60 & -741 \\
\hline 17 & L2 & L3 & L2 & 74.0 & 1.20 & 1.40 & 2.90 & -726 \\
\hline 18 & L2 & L3 & L3 & 78.0 & 2.10 & 2.00 & 1.80 & -734 \\
\hline 19 & L3 & L1 & $\mathrm{L} 1$ & 69.0 & 1.00 & 1.30 & 1.70 & -724 \\
\hline 25 & L3 & L3 & L1 & 68.0 & 0.95 & 1.30 & 1.00 & -728 \\
\hline 26 & L3 & L3 & L2 & 67.0 & 1.10 & 1.50 & 1.40 & -724 \\
\hline 27 & L3 & L3 & L3 & 65.0 & 1.20 & 1.40 & 1.10 & -722 \\
\hline
\end{tabular}


Table 11. Induction Hardening Test Results Materials: AISI 6150

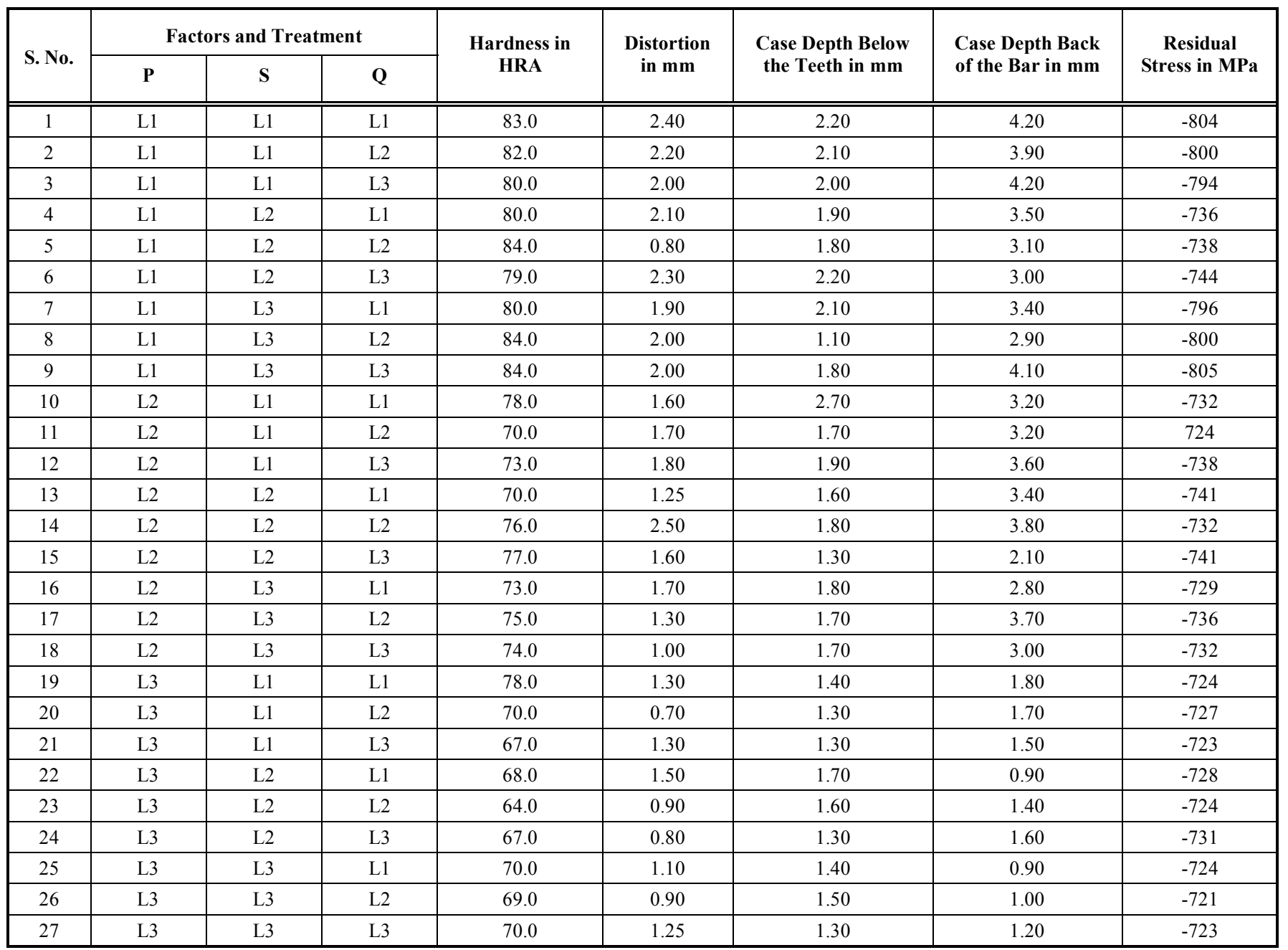

Table 12. Residual Stress and Micro Hardness Values of the Induction Hardened Component for the Selected Set of Trials Material: AISI 1040

\begin{tabular}{|c|c|c|c|c|}
\hline Depth Beneath the Surface in $\mathrm{mm}$ & Trial 6 & Trial 16 & Trial 6 & Trial 16 \\
\hline 0.1 & 644 & 636 & -747 & -738 \\
\hline 0.2 & 636 & 627 & -742 & -734 \\
\hline 0.3 & 625 & 624 & -741 & -731 \\
\hline 0.5 & 612 & 609 & -731 & -724 \\
\hline 0.6 & 608 & 605 & -725 & -719 \\
\hline 0.7 & 604 & 598 & -720 & -714 \\
\hline 0.8 & 594 & 587 & -719 & -708 \\
\hline 0.9 & 591 & 583 & -715 & -702 \\
\hline
\end{tabular}

depth more will be the residual stress formed. The residual stresses formed are compressive in nature and so it may improve the fatigue strength of the material [15].
The surface hardness in HRA, Distortion in mm, Case depth below the teeth of the Rack in mm, Case depth back of the Rack in $\mathrm{mm}$ and Residual stress in MPa for different experimental combinations of Induction hardened specimens are shown in Tables $\mathbf{1 0}$ and $\mathbf{1 1}$. 


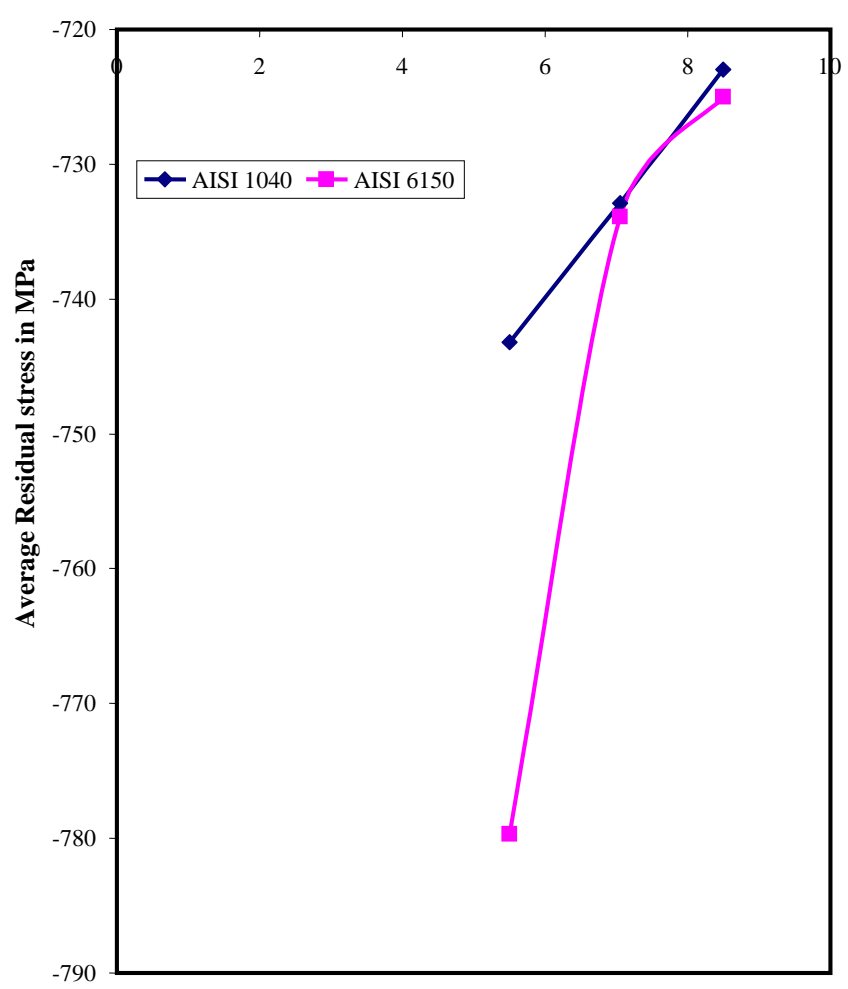

Power potential in kW/ sq.inch

(a)

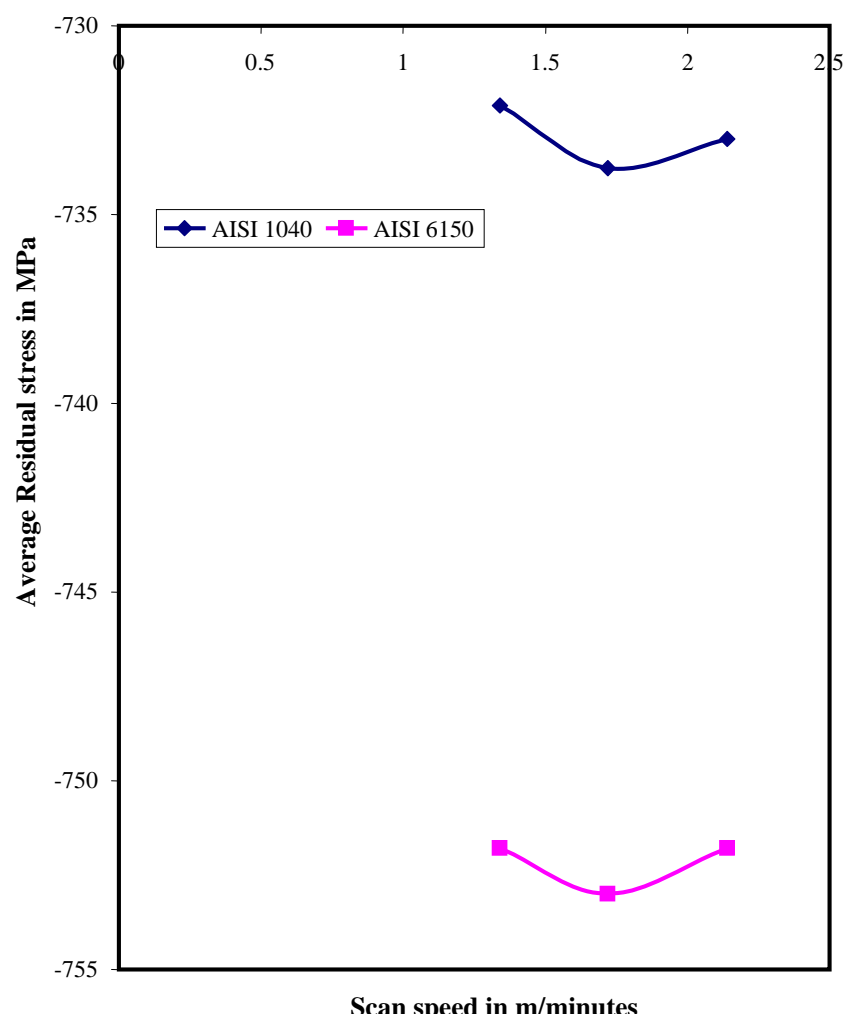

(b)
(Fig. 6) contd.....

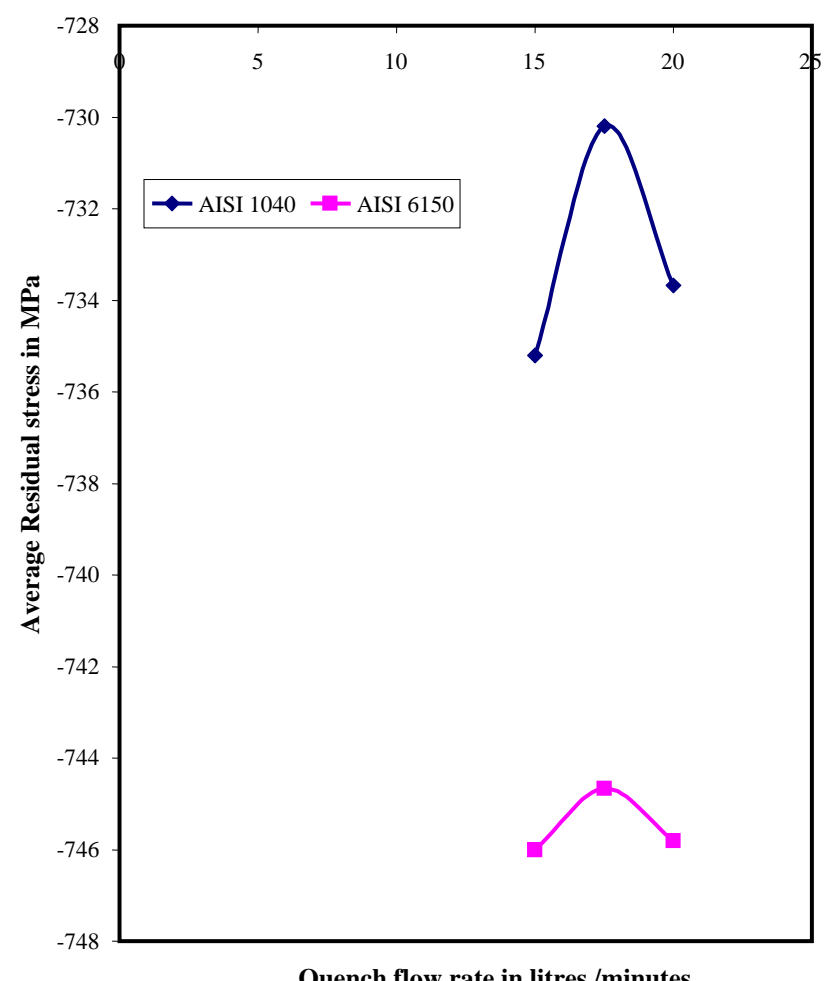

(c)

Fig. (6). (a-c) Process variables vs residual stress.

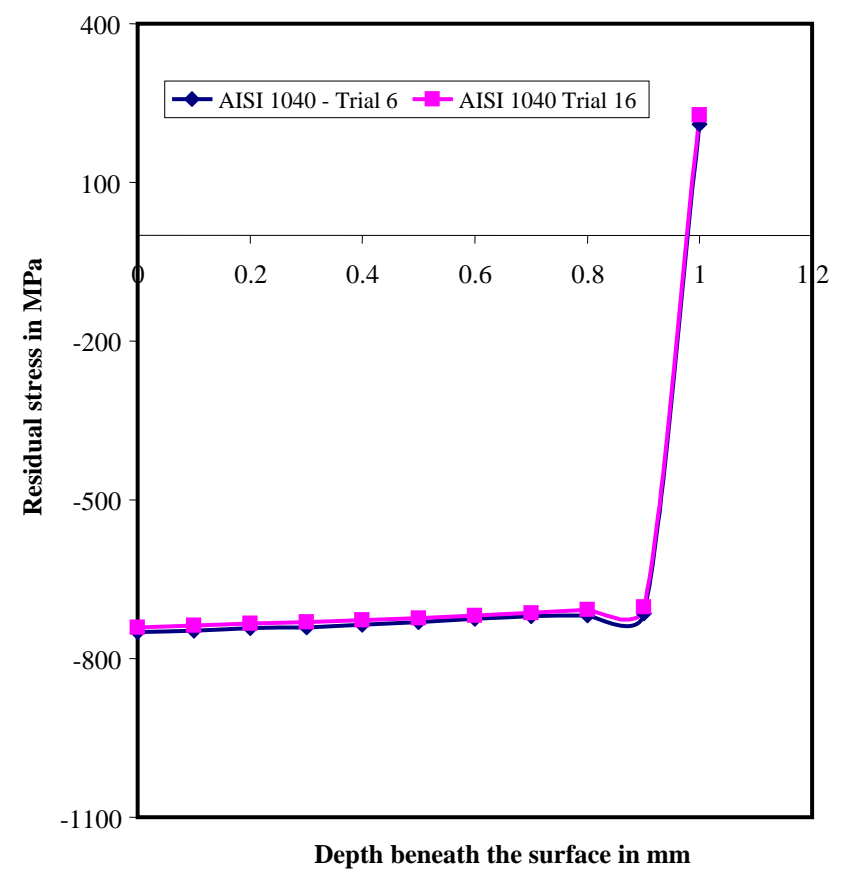

Fig. (7). Depth beneath the surface $v s$ residual stress (AISI 1040 steel material - induction hardening process). 
Table 13. Residual Stress and Micro Hardness Values of the Induction Hardened Component for the Selected Set of Trials Material: AISI 6150

\begin{tabular}{|c|c|c|c|c|}
\hline Depth Beneath the Surface in $\mathrm{mm}$ & \multicolumn{2}{|c|}{ Micro Hardness in VHN } & \multicolumn{2}{|c|}{ Residual Stress in MPa } \\
\hline 0.1 & 664 & 652 & -792 & -721 \\
\hline 0.2 & 652 & 649 & -787 & -716 \\
\hline 0.4 & 632 & 628 & -752 & -705 \\
\hline 0.5 & 628 & 624 & -743 & -698 \\
\hline 0.6 & 620 & 617 & -739 & -674 \\
\hline 0.7 & 610 & 604 & -726 & -668 \\
\hline
\end{tabular}

The magnitude and the nature of the residual stresses left after heat treatment at different operating conditions have been measured by the X-ray diffraction techniques using the Residual stress analyzer. Residual stress analysis indicates that Induction hardening can give a compressive residual stress of (-) $800 \mathrm{MPa}$ for the Low alloyed Medium carbon steels [16]. However, Gas carburising can give a compressive residual stress of (-) $400 \mathrm{MPa}$ for Low alloyed Low carbon steels [17].

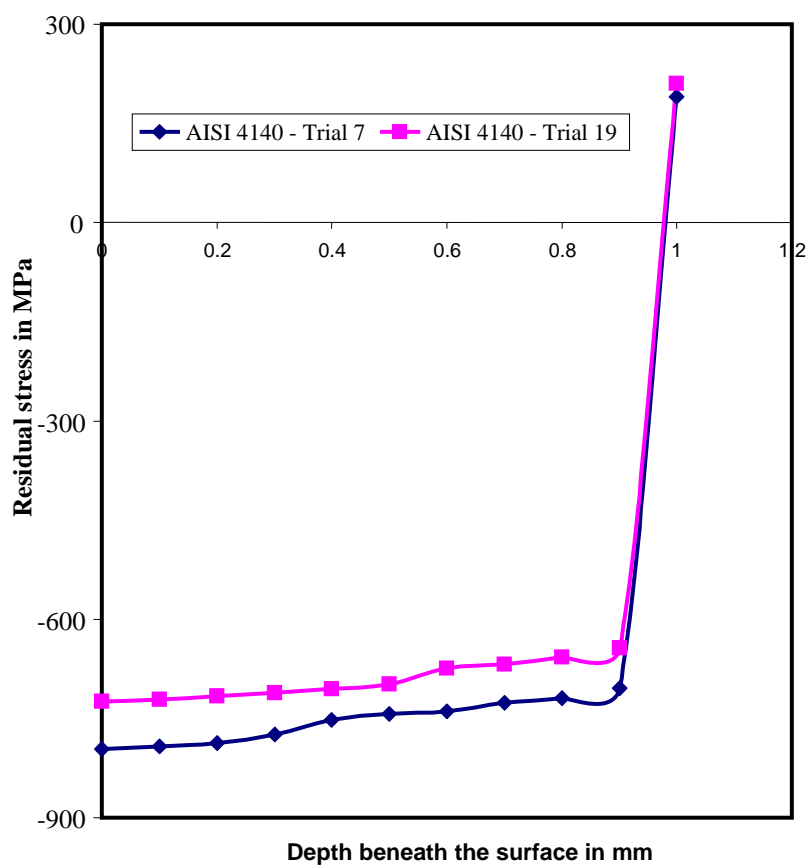

Fig. (8). Depth beneath the surface $v s$ residual stress (AISI 4140 steel material - induction hardening process).
It is inferred from the graphs (Figs. (2a-e, 6a-c) that the optimum results gives the maximum compressive residual stress in both the Gas carburizing and Induction hardening process irrespective of the mechanisms involved in the process. Figs. $(\mathbf{3}, \mathbf{4}, \mathbf{7}, \mathbf{8})$ shows the Residual stress beneath the surface of the pinion and Rack materials respectively. The X-ray diffraction test shows that the distribution of residual stress is uniform both on the surface and beneath the surface. The magnitude and distribution of residual stress obtained from the experimental work agrees with the FEM results given by Dong-hui $X u$ and Zhen-Bhang Kuang (1996) [18].

\section{CONCLUDING REMARKS}

- Micro hardness analysis shows that there is a gradual decrease of hardness from surface to sub-surface.

- $\quad$ Study indicates that more the hardness and case depth more will be the residual stress formed. The residual stresses formed are compressive in nature and it improves the fatigue strength of the material.

- Residual stress analysis indicates that Induction hardening can give a compressive residual stress of (-) $800 \mathrm{MPa}$ for the Low alloyed Medium carbon steels. However, Gas carburising can give a compressive residual stress of (-) $400 \mathrm{MPa}$ for Low alloyed Low carbon steels.

- $\quad$ The X-ray diffraction test shows that the distribution of residual stress is uniform both on the surface and beneath the surface. The magnitude and distribution of residual stress obtained from the experimental work agrees with the FEM results given by Donghui Xu and Zhen-Bhang Kuang (1996) [19].

\section{ACKNOWLEDGEMENTS}

The authors are thankful to Rane (Madras) Pvt. Ltd., Thirubhuvanai, Pondicherry and IGCAR Kalpakkam for providing the experimental, testing and measurement facilities. 


\section{REFERENCES}

[1] Gergely M, Somogyi SZ, Buza G. Calculation of transformation sequences in quenched steel components to help predict internal stress distribution. Mater Sci Technol 1985; 1: 893-8.

[2] Kamamoto S, Nishimori T, Kinoshita S. Analysis of residual stress and distortion resulting from quenching in large low-alloy steel shafts. Mater Sci Technol 1985; (1): 798-804.

[3] Rai JK, Mishra A, Rao UR. Residual stresses due to quenching process. Int J Mach Tool Des Res 1979; 20: 1-8.

[4] Mitra PK, Paul S, Chatterjee S. Treatment, structure, corrosion, correlation of AISI 8640 Steel. IE (I) J - MM 2004; 85: 33-6.

[5] Mitter W, Rammerstorfer FG, GrundlerO, Wiedner G. Discrepancies between calculated and measured residual stresses in quenched pure iron cylinder. Mater Sci Technol 1985; 1: 793-7.

[6] Rathbun FO, Coffin LF. An experimental investigation of residual stresses in quenched flat plates. Research and Development Centre, Schenectady, New York 1975.

[7] Ravindran Nair R, Natarajan R, Rao URK. Analysis of residual stresses due to quenching considering microstructural transformations. Int J Mach Tool Des Res 1982; 22: 309-19.

[8] Sen S, Aksakal B, Ozel A. Transient and residual thermal stresses in quenched cylindrical bodies. Int J Mech Sci 2000; 42: 2013-29.

[9] Steel products Manual tool steels. American Iron and Steel institute 1976.

[10] Suryanarayana AVK. Testing of metallic materials. New Delhi: Prentice-Hall of India 1979.
[11] Kristoffersen H, Vomacka P. Influence of process parameters for induction hardening on residual stresses. Int J Mater Des 2001; 22: 637-44.

[12] Li YY, Chen Y. Modeling quenching to predict residual stress and microstructure distribution. Trans ASME 1988, vol. 110; pp. 373-8.

[13] Liu CC, Liu Z, Xu XJ, Chen GX, Wu JZ. Effect of stress on transformation and prediction of residual stresses. Int J Mater Sci Technol 1998; 14: 747-50.

[14] Schroder R. Influences on development of thermal and residual stresses in quenched steel cylinders of different dimensions. Mater Sci Technol 1985; 1: 754-64.

[15] Weiner JH, Huddleston JV. Transient and residual stresses in heat treated cylinders. ASME J Appl Mech 1959; 26: 31-9.

[16] Woodard PR, Chandrasekar S, Yang HTY. Analysis of temperature and microstructure in the quenching of steel cylinders. Metallic Mater Trans B 1999; 30B: 815-22.

[17] Yuan F-R, Wu S-L. Transient-temperature and residual - stress fields in axisymmetric metal components after hardening. Mater Sci Technol 1985; 1: 851-6.

[18] Xu Dh, Kuang ZB. A study on the distribution of residual stress due to surface induction hardening. Int J Eng Mater Technol 1996; 118: 571-5.

[19] Xu D-h, Kuang Z-B. A Study on the distribution of residual stress due to surface induction hardening. Int J Eng Mater Technol 1996; 118: $571-5$.

(C) Palaniradja et al.; Licensee Bentham Open.

This is an open access article licensed under the terms of the Creative Commons Attribution Non-Commercial License (http://creativecommons.org/licenses/by-nc/ 3.0/) which permits unrestricted, non-commercial use, distribution and reproduction in any medium, provided the work is properly cited. 